\title{
An Improved AOMDV Routing Protocol for Airspace Communication Network
}

\author{
Xi Zhang, Tao Zhang \\ School of Electronic and Information Engineer, Beihang University, Beijing, China \\ Email:1255248430@qq.com
}

How to cite this paper: Zhang, $X$. and Zhang, T. (2017) An Improved AOMDV Routing Protocol for Airspace Communication Network. Int. J. Communications, Network and System Sciences, 10, 157-166. https://doi.org/10.4236/ijcns.2017.108B017

Received: May 28, 2017

Accepted: August 11, 2017

Published: August 14, 2017

\begin{abstract}
The airspace communication network based on spacecraft has a wide range of applications in regional information enhancement and emergency communication. In this paper, a routing algorithm for congestion degree detection of multipath routing (CD_AOMDV) is proposed. The method of combining the whole congestion degree detection and local congestion degree detection before service initiation is adopted. Timely and accurate judgment of the congestion degree reduced the loss rate of the hot nodes, so the average packet loss rate reduced. Simulation results show that compared with the traditional AOMDV protocol, the CD_AOMDV proposed in this paper has reduced the packet loss and improved delay performance, which is more suitable for the airspace communication network.
\end{abstract}

\section{Keywords}

Airspace Communication Network, AOMDV Routing Protocol, Nodes Mobility, SNS Simulation Platform

\section{Introduction}

The spacecraft has the advantages of long stay time, high precision and high coverage area. Therefore, airspace communication network which is based on spacecraft supports fast access of mobile nodes such as UAVs and ground mobile nodes in the coverage area of the airspace. Airspace communication network has a wide range of applications in the area of information enhancement, emergency communications.

At present, there are few research achievements about the technology of airspace communication network both at home and abroad. International research on airspace communication is mainly focused on air traffic control [1], airspace communication network architecture [2], security problems in air transport systems [3], multi-frequency data communication [4], navigation signal detection 
[5], etc. Less attention has been paid to the routing of the airspace communication network. In fact, due to the constantly movement of UAVs and ground mobile nodes, the network topology keeps changing. Because of the dynamic topology and limited transmission bandwidth, the airspace communication network has Ad hoc network characteristics.

In the existing routing protocols, according to the generation time of the routing table, the Ad hoc network routing protocols are divided into table-driven routing protocol and on-demand routing protocol [6]. Because the on-demand routing protocols (such as DSR [7], TORA [8], AODV [9]) just discovery and maintenance the required routing, the on-demand routing protocols are faster than the table-driven routing protocols, and the memory footprint of the on-demand routing protocols is smaller and when topology changes they use less time to response [10] [11]. So the on-demand routing protocols are more suitable for airspace communication network.

However, for the airspace communication network, because the aerostat nodes often have better ability (greater throughput, routing capacity, etc.) so they are in a special hub position in the airspace communication network. It usually makes the aircraft nodes to become hot nodes in the network. When the frequency of session-initiated or the volume of session increases, it is usual to see link congestion of the links between UAVs with aerostats. In this case, if the aerostats can't be selected repeatedly when select multipath, the success rate of the session will reduce greatly. If the aerostats can be selected repeatedly, when the aerostats become hot nodes, it is difficult to deal with problems such as large number of packet loss and rapid increase in delay.

The AOMDV protocol is mainly applied to the network of equal nodes [12]. The AOMDV protocol is difficult to apply directly to the space network which node has different capability and nodes are easy to become hot nodes. In this paper, an improved AOMDV protocol (CD_AOMDV protocol) is proposed to reduce the packet loss rate of the aerostats when they become hot nodes. The algorithm improves the efficiency of network transmission by detecting the link congestion degree and selecting the path with the lowest congestion degree.

\section{Ease of Use}

\section{The Problem to Apply AOMDV in the Airspace Communication Network}

Simulation results show that when using the AOMDV protocol (shown in Figure 1) with the increase of the traffic volume, the packet loss rate and the endto-end delay increases rapidly in the air traffic network. After analysis, the reason is that in many cases AOMDV can only find one available path (which contains the aerostats) in the airspace communication network. What is more serious is that the aerostats are easy to become hot nodes.

The scenario parameters for Figure 1 are shown in Section 3.1 of this article. Simulation shows that with the increase in session, the packet loss rate of aerostat rise rapidly. Packet loss first appeared in the aerostat, with the increase in 


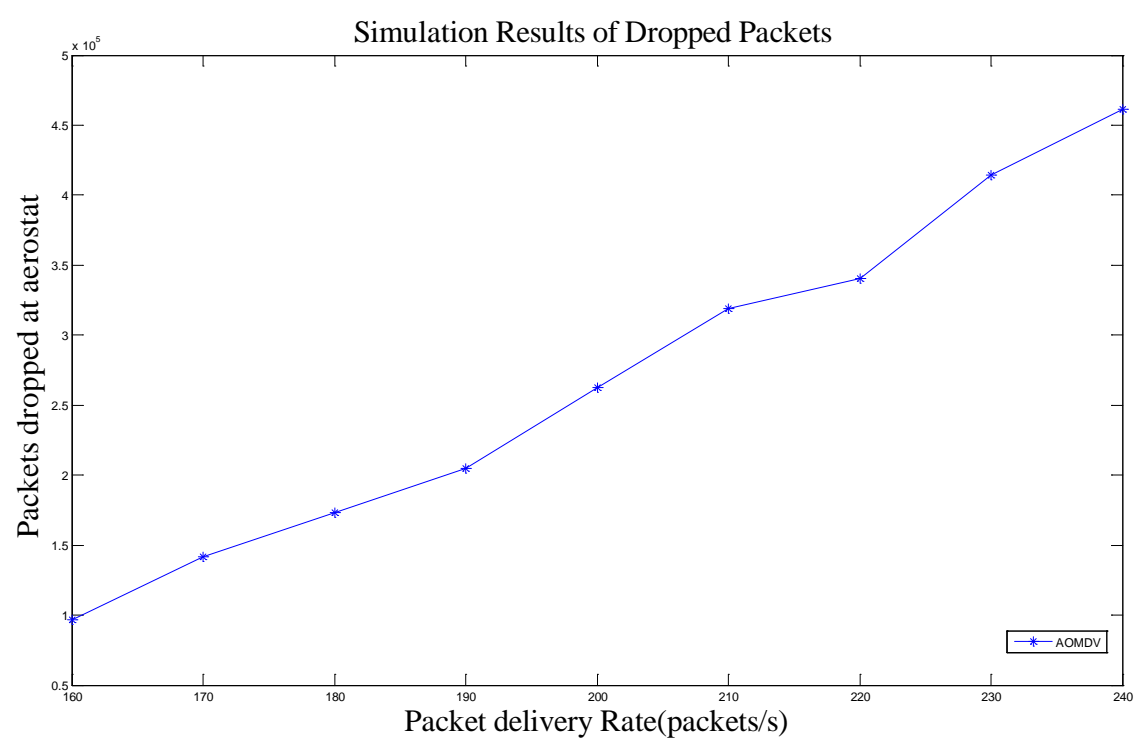

Figure 1. Packet loss rate of aerostats.

session, UAVs also began to lost packets, the percentage of the loss rate of the aerostats slowly decline. However, in general, the aerostats still caused $80 \%$ of the packet loss rate. Therefore, reducing packet loss rate of the aerostats has become an important problem of the airspace communication network.

In the airspace communication network, aerostats are bound to become hot nodes due to the particularity of the network. This feature challenges the AOMDV protocol. The AOMDV protocol are suitable for networks with equal nodes, it should be improved to apply in the airspace communication network. Before initial every session, the nodes need to detect the congestion degree to avoid hot nodes. For middle nodes to transmit packets, next hop and link with less congestion degree will be chosen.

The improved protocol can take advantage of the big bandwidth of the aerostats and maintain the superiority of the AOMDV algorithm when there is no congestion. When the performance of the aerostats is getting worse, other path with less congestion will be selected to transmit data. The problem of packets loss and delay is solved.

\section{CD_AOMDV Routing Protocol}

In order to solve the problem of network congestion caused by hot nodes in the airspace communication network, the CD_AOMDV protocol is proposed in this paper to improve the AOMDV protocol. The protocol records the congestion degree of each path in the route path during the route discovery, and sorts congestion degree of the discovered paths. When the HELLO messages are exchanged between neighbors, the link congestion degree will be passed as one of the parameters.

\subsection{Improved Route Discovery and Maintenance}

During the route discovery, the intermediate node adds the current link conges- 
tion degree to RREP. The source node can calculate the congestion degree of each path after receiving RREP. The congestion degree of each path is equal to the highest congestion degree of the path.

In this paper, the source node calculates the congestion degree for each path and determines which path to use. Suppose that there are $k$ paths, and the congestion degree of each path is $p(i)$. The congestion degree for each segment of the $i$ path is $x_{0}, x_{1}, \cdots, x_{n}$ (in this scenario, $n \leq 8$ ).

That is:

$$
\begin{gathered}
p(i)=\arg \max \left(x_{t}\right), t=0,1,2, \cdots, 7 \\
x_{t}=\mathrm{l} /\left(\max _{\text {length }} * B w\right)
\end{gathered}
$$

$l$ is the length of the queue when the route is discovered, $\max _{\text {length }}$ is the maximum length of the queue buffer, $B w$ is link bandwidth. This formula comprehensively reflects the current congestion and processing ability of each link.

After calculating the congestion degree for each path, the source node will select the path with the lowest congestion degree to transmit packets, that is:

$$
\text { path }=\arg \min (p(i)), i=0,1,2, \cdots, k
$$

As shown in Figure 2, in dealing with RREQ packets, the difference between

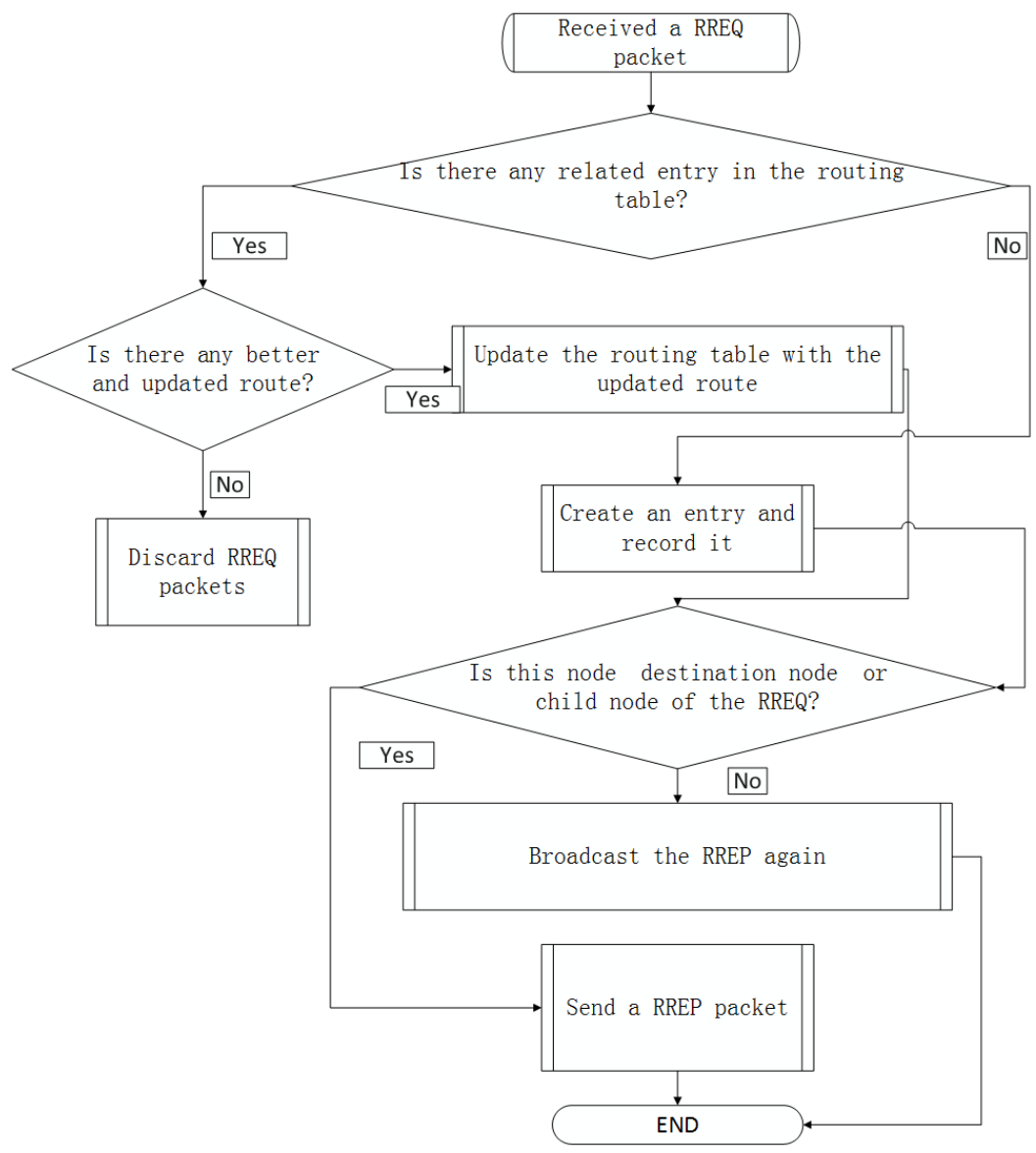

Figure 2. Packet processing of CD_AOMDV protocol when receiving RREQ. 
CD_AOMDV and AOMDV protocol is that the intermediate node or destination node will add the link congestion degree when creating RREP.

As shown in Figure 3, in dealing with RREP, the difference between CD AOMDV and AOMDV protocol is that the source node will compare, determine and record link congestion degree, the intermediate node will record the link congestion degree.

After the route discovery, assume that there are $k$ neighbors in the process of forwarding packets from the source node or the intermediate node. The calculation formula of congestion degree of the neighbors is the same as the calculation formula of discovery route. According to the result of the link detection $x(i)$, we select the next hop path as the formula below:

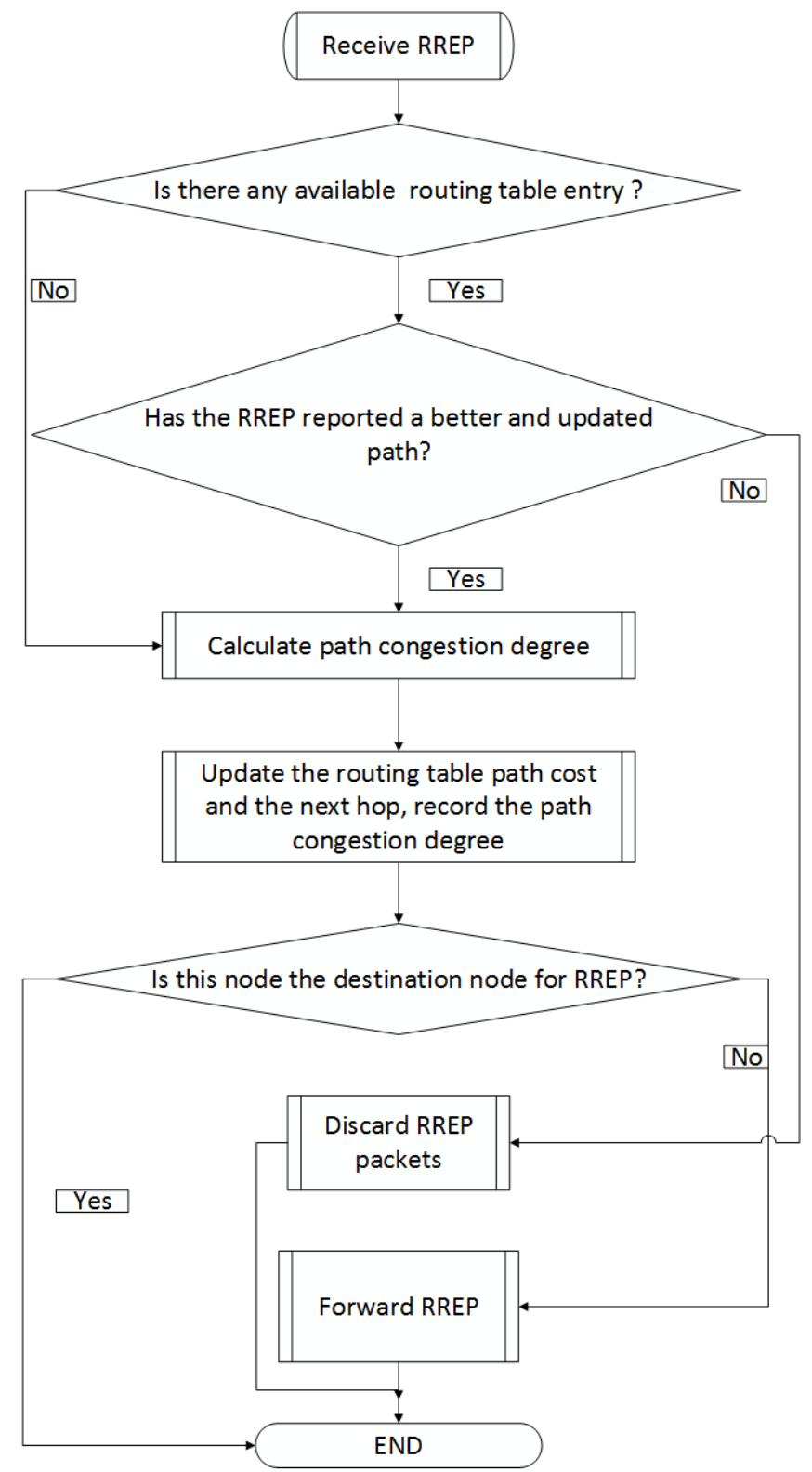

Figure 3. Packet processing of CD_AOMDV protocol when receiving RREP. 


$$
\text { path }=\min \arg (x(i)), i=0,1,2, \cdots, k
$$

As shown in Figure 4, before the source nodes send the packets and the intermediate nodes forward packets, they will check the link congestion degree and select the path whose congestion is lowest.

During the routing maintenance, CD_AOMDV uses the HELLO messages to interact with the "congestion degree" between the neighbor nodes.

As in the airspace communication network, the number of hops between the source and destination nodes does not exceed eight hops, and more than eight hops are considered invalid routes. The CD_AOMDV protocol adds eight records of the link congestion degree at the end of the RREP. The new format of RREP is shown in Figure 5.

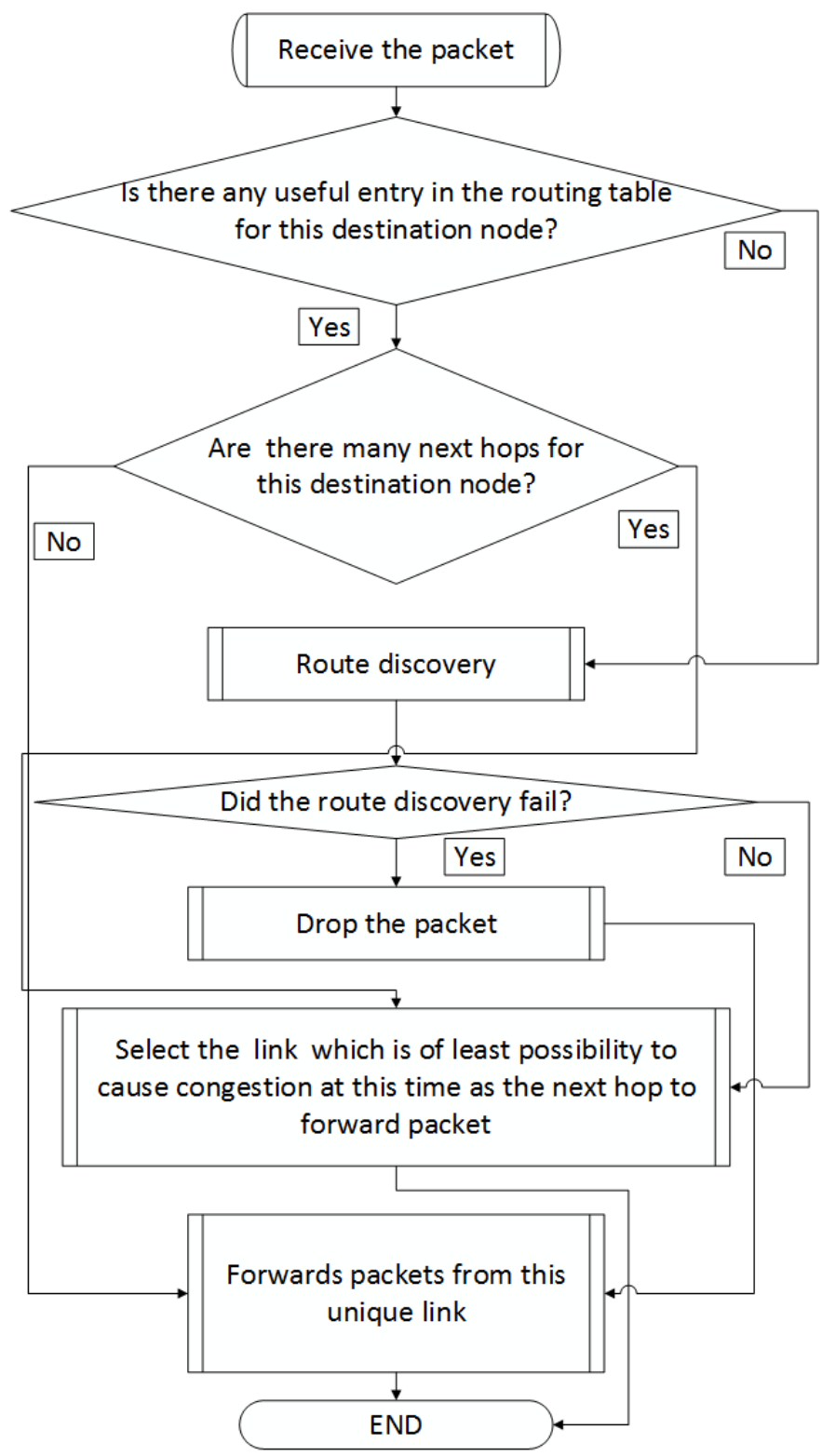

Figure 4. Packet processing of CD_AOMDV protocol when receiving data. 


\begin{tabular}{|c|c|c|c|}
\hline $0-7$ & $8-F$ & \multicolumn{2}{|l|}{$0-7$} \\
\hline Type & \multicolumn{2}{|l|}{ Reserved } & Hops \\
\hline \multicolumn{4}{|c|}{ Destination node IP address } \\
\hline \multicolumn{4}{|c|}{ Destination node serial number } \\
\hline \multicolumn{4}{|l|}{ Source node IP address } \\
\hline \multicolumn{4}{|l|}{ First hop IP address } \\
\hline \multicolumn{2}{|l|}{$1^{\text {th }}$ congestion degree } & \multicolumn{2}{|c|}{$2^{\text {th }}$ congestion degree } \\
\hline \multicolumn{2}{|l|}{$3^{\text {th }}$ congestion degree } & \multicolumn{2}{|c|}{$4^{\text {th }}$ congestion degree } \\
\hline \multicolumn{2}{|l|}{$5^{\text {th }}$ congestion degree } & \multicolumn{2}{|c|}{$6^{\text {th }}$ congestion degree } \\
\hline \multicolumn{2}{|l|}{$7^{\text {th }}$ congestion degree } & \multicolumn{2}{|c|}{$8^{\text {th }}$ congestion degree } \\
\hline
\end{tabular}

Figure 5. RREP message format.

\subsection{Improved Routing Table}

In a mobile Ad hoc network, the AOMDV protocol sets "valid time period" for each path to ensure that the paths in the routing table are available at the time of forwarding, and when the idle time is too long some paths will be discarded.

In the airspace communication network, the CD_AOMDV protocol will no longer periodically initiate the routing request. In order to reduce the frequency of route initiation, only when the destination is needed and there is no routing entry the node starts route discovery.

In order to record the congestion degree, the routing table is changed; the routing information list of the improved routing table is shown in Figure 6.

\subsection{Experiment Simulation}

The scenario parameters are shown in Table 1 . The simulation scene size is (1.2 $\left.\times 10^{6} \mathrm{~m}\right) \times\left(1.2 \times 10^{6} \mathrm{~m}\right)$ and it is evenly divided into four areas in both vertical and horizontal direction. In each area, one aerostat is cruising around the center of the area with a radius of $1 / 4$ of the area length. The angular velocity of the aerostat is between $100 \mathrm{rad} / \mathrm{s}$ and $200 \mathrm{rad} / \mathrm{s}$. So in total, there are 4 aerostats, two to six UAVs are randomly distributed near the aerostat. At the beginning of the simulation, the destination addresses are randomly generated within the scene, and the UAVs continue to fly to a new destination with a flight speed between $300 \mathrm{~m} / \mathrm{s}$ and $400 \mathrm{~m} / \mathrm{s}$. UAVs will connect to a new aerostat will they fly from one area into another. Packets are sent from UAVs to UAVs, the aerostats just forward packets instead of sending or receiving them. The simulation last 1,000,000 seconds, every 100 seconds as a new cycle, three new sessions are evenly produced in every cycle. Session duration is random, packet length are 1000 bytes. The packet time interval is decided by the session duration and session load.

Figure 7 shows that the packet loss rates of the AOMDV and CD_AOMDV protocols are both increasing as the packet transmission rate increases. But as the packet transmission rate becomes faster and faster, network congestion gets more and more serious. As AOMDV protocol only consider the number of hops, 


\begin{tabular}{|l|l|l|l|l|}
\hline Next hop & Hops & First Hop & $\begin{array}{l}\text { Next hop } \\
\text { congestion } \\
\text { degree }\end{array}$ & $\begin{array}{l}\text { Path } \\
\text { congestion } \\
\text { degree }\end{array}$ \\
\hline Next hop & Hops & First Hop & $\begin{array}{l}\text { Next hop } \\
\text { congestion } \\
\text { degree }\end{array}$ & $\begin{array}{l}\text { Path } \\
\text { congestion } \\
\text { degree }\end{array}$ \\
\hline$\ldots . .$. & & \\
\hline
\end{tabular}

Figure 6. Routing information list.

Table 1. Simulation parameters.

\begin{tabular}{cc}
\hline Parameter Type & Parameter Value \\
\hline Simulation areasize/m $\times \mathrm{m}$ & $\left(1.2 \times 10^{6}\right) \times\left(1.2 \times 10^{6}\right)$ \\
Simulation time/s & 500 \\
Aerostat/ & 4 \\
UAVs/ & 20 \\
Packet size/Bytes & 1000 \\
Session interval/s & 33 \\
Aerostat movement model & Circular motion \\
UAV movement model & Uniform linear motion \\
Aerostat angular velocity/(rad/s) & $100-200$ \\
UAV speed/(m $\left.\times \mathrm{s}^{-1}\right)$ & $300-400$ \\
Wireless transmission \\
radiusbetween aerostats/m \\
Wireless transmission \\
radius between UAVS/m \\
Wireless transmission radius \\
between aerostat and UAV/m \\
Link bandwidth between aerostats/(bit/s) \\
Link bandwidth between UAVs/(bit/s) \\
Link bandwidth between aerostat and \\
UAV/(bit/s)
\end{tabular}

hot nodes will drop lots of packets and the network packet loss rate increases dramatically. As the CD_AOMDV choose the path with bigger bandwidth, the traffic is balanced and the packet loss rate will increase much more slowly.

Figure 8 shows that the end-to-end delay of the AOMDV and CD_AOMDV protocols is increasing as the packet transmission rate increases. When the packet transmission rate is not very fast, that is, the link load is not very heavy, the delay of AOMDV protocol is smaller because of the choice of the shortest path. But with the increase of link load, there will be a large number of packets staying in some hot nodes, resulting in the decline of entire network performance. But the delay of CD_AOMDV increases much more slowly because the packets will be forwarded faster without choosing the busy link. 


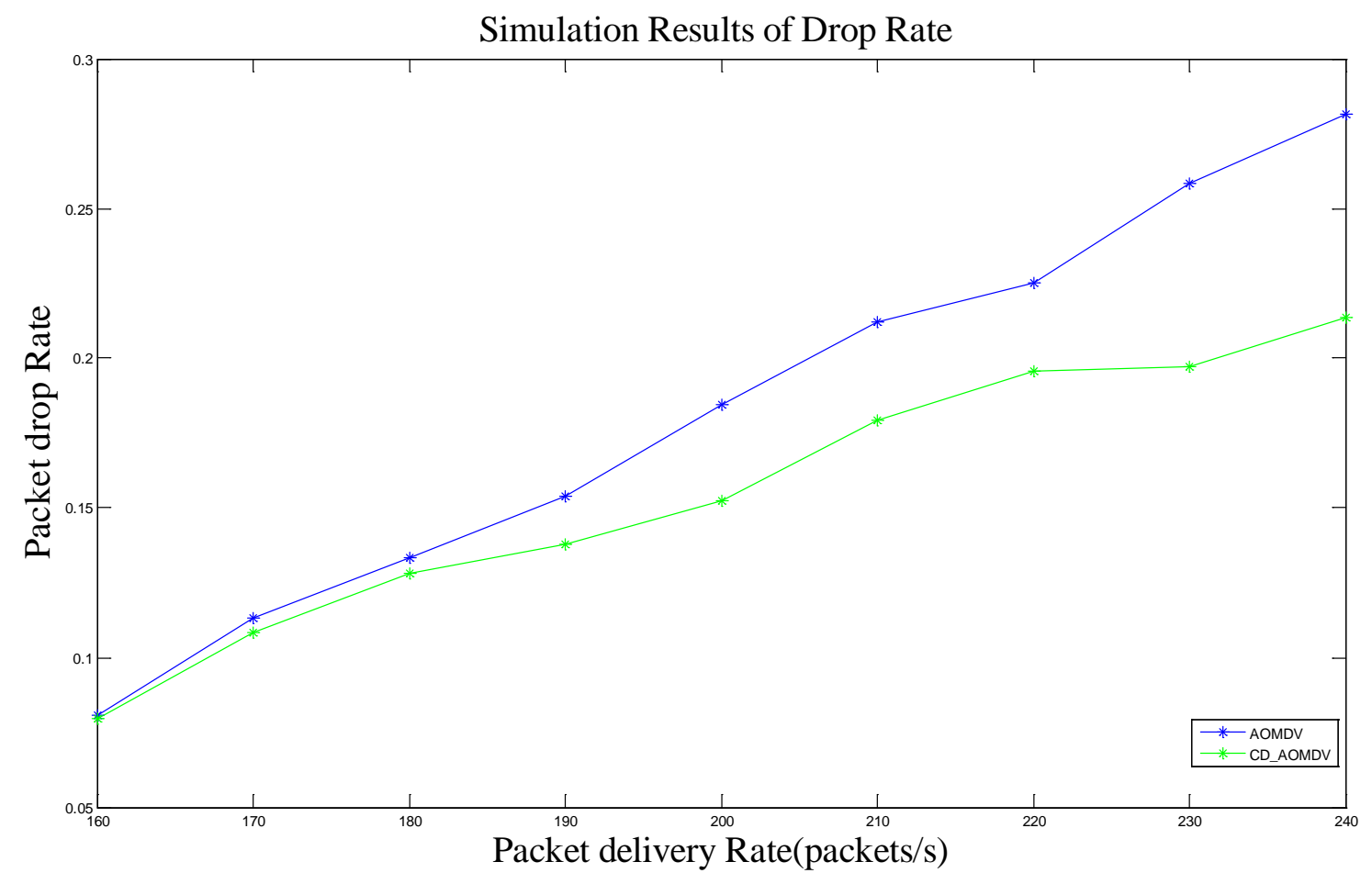

Figure 7. Packet loss rate comparison at different packet transmission rates.

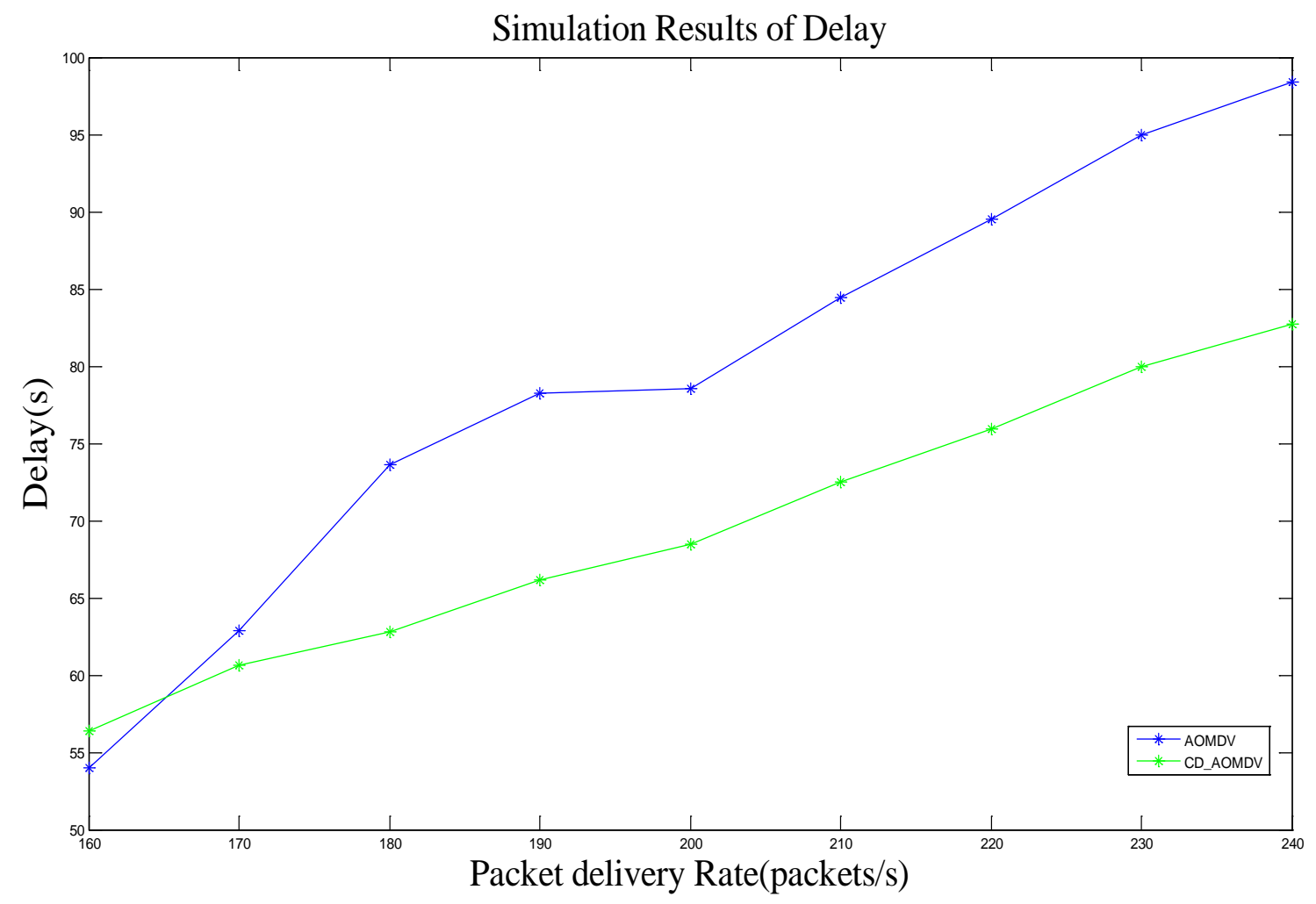

Figure 8. End-to-end delay comparison at different packet transmission rates.

In summary, in the process of increasing the link load, in the airspace communication network, some nodes especially the aerostats can easily become hot 
nodes. By making full use of the information of multiple routing discovery and neighbor interaction, CD_AOMDV protocol selects the path of the lowest congestion degree. Thus the packet loss rate and delay are both increasing slowly.

\section{Acknowledgements}

This work was supported by the National Key Research and Development Program of China (No. 2016YFB1200102), the National Nature Science Foundation of China (No. 91638301).

\section{References}

[1] Kampichler, W. and Eier, D. (2016) Location Based Communication Services for UAS in the NAS. 2016 IEEE/AIAA 35th Digital Avionics Systems Conference (DASC), Sacramento, CA, 25-29 September 2016, 1-7. https://doi.org/10.1109/dasc.2016.7778036

[2] Monticone, L.C., Snow, R.E. and Ribeiro, L.Z. (2014) Load-Balancing Algorithms for Multifrequency Data Communications. 2014 Integrated Communications, Navigation and Surveillance Conference (ICNS), Herndon, VA, 8-10 April 2014, Q4-1Q4-13. https://doi.org/10.1109/icnsurv.2014.6820013

[3] Strohmeier, M., Lenders, V. and Martinovic, I. (2015) On the Security of the Automatic Dependent Surveillance-Broadcast Protocol. IEEE Communications Surveys \& Tutorials, 17, 1066-1087. https://doi.org/10.1109/COMST.2014.2365951

[4] Liu, Y. and Zhu, Y. (2013) A Collaborative Integrity Monitor Algorithm for Low Space Aviation under Limited Number of Navigation Satellites. 2013 International Conference on Connected Vehicles and Expo (ICCVE), Las Vegas, NV, 2-6 December 2013, 910-915. https://doi.org/10.1109/ICCVE.2013.6799925

[5] Zhang, P. and Cui, Y. (2010) Research Progress of Routing Algorithm for Mobile Ad Hoc Networks. Computer Science, No. 1, 10-22+38.

[6] Royer, E.M. and Toh, C.-K. (1999) A Review of Current Routing Protocols for Ad Hoc Mobile Wireless Networks. IEEE Personal Communications, 6, 46-55. https://doi.org/10.1109/98.760423

[7] Johnson, D.B. (2003) The Dynamic Source Routing Protocol for Mobile ad Hoc Networks. Draft-ietf-manet-dsr-09.txt.

[8] Park, V. and Corson, M.S. (1997) Temporally-Ordered Routing Algorithm (TORA) Version 1 Function Specification. Internet-Draft, draft-ietf-manet-tora-spec-00.txt.

[9] Perkins, C.E. and Royer, E.M. (1999) Ad-Hoc on-Demand Distance Vector Routing. Proceedings of Mobile Computing System and Applications (WMCSA99), 25-26 February 1999, 90-100. https://doi.org/10.1109/MCSA.1999.749281

[10] Marina, M.K. and Das, S.R. (2006) Ad Hoc on Demand Multipath Distance Vector Routing. Wireless Communication and Mobile Computing, 6, 969-988. https://doi.org/10.1002/wcm.432

[11] Yu, B.-G., Yu, C.-F. and Liu, G. (2014) Communication Analysis of Multiple Mobile Nodes Based on AODV and AOMDV Routing Protocol. Value Engineering, 15, 194-195.

[12] Li, J., Huang, T.H., Cui, G.S. and Yang, M. (2015) Research on Link Expiration Time-Based AOMDV Routing Protocol. Computer Applications and Software, 32, 132-135. 
Submit or recommend next manuscript to SCIRP and we will provide best service for you:

Accepting pre-submission inquiries through Email, Facebook, LinkedIn, Twitter, etc. A wide selection of journals (inclusive of 9 subjects, more than 200 journals)

Providing 24-hour high-quality service

User-friendly online submission system

Fair and swift peer-review system

Efficient typesetting and proofreading procedure

Display of the result of downloads and visits, as well as the number of cited articles Maximum dissemination of your research work

Submit your manuscript at: http://papersubmission.scirp.org/

Or contact ijcns@scirp.org 